Nations, based in the first instance on understanding between Great Britain, the United States and the U.S.S.R., a great opportunity has opened, and although the task will be heavy it can be achieved if we do not forget our lessons, and make co-operation in peace as true and effective as in the years of war.

\section{Colonial Policy}

Viscount Cranborne, until recently Secretary of State for the Colonies, replied on behalf of the Government in a debate in the House of Lords on December 3 on Colonial affairs. The keynote of his speech was the diversity of the Colonial territories. He remarked that ever since the fall of Malaya there has been a stream of criticism against the administration of the Colonies. That disaster was due, according to some, to the fact that the local peoples had not been suffi. ciently associated with the government of their country. This explanation, however, cannot apply to Siam, an independent State, or to the excellent administrative system of the Dutch East Indies or of the Philippines. British policy gave Malaya a long period of internal peace, justice and prosperity. The proposal for a Colonial charter presupposes a uniformity which is unattainable and probably undesirable in the British Empire. The Empire consists of a diversity of countries and peoples in all stages of development, and its administration is characterized by great variety and flexibility. There is no cut and dried pattern ; local systems have been adapted and adopted, and there has been gradual evolution in each territory of a form of government which seems best suited to promote the moral and material welfare of the people, with the ultimate aim of self. government.

A fundamental step in advancing to self-government is the provision of education. Surveying the position, Lord Cranborne said that, in the field of mass education, we have to meet first widespread illiteracy. Programmes for adult and community education are being prepared. Elementary education is spreading in Nigeria, the Gold Coast, Uganda, Mauritius and the West Indies, where Sir Frank Stockdale, comptroller for development and welfare, has been working for two years. Higher education is being developed at Achimota in West Africa, and at Makerere in East Africa; in Ceylon, the university college has been raised to the status of a university; in West Africa there is a scheme for an institute of arts, crafts and social sciences. Further, much consideration is being given to the education of women and girls. Medical schools are working in East and West Africa, in Ceylon, Malta and Fiji, and important investigations are being carried out by British organizations and by the Rockefeller Founda. tion. Social security rests, so far as the Colonial Empire is concerned, on economic security, and this in turn on agriculture; steps for the production of food for local use have been speeded up, and mixed farming has been promoted. Labour conditions have been improved, and Lord Cranborne referred to the Exchequer grant of $£ 5,000,000$ a year under the Colonial Development and Welfare Act for approved schemes advanced by Colonial Governments.

\section{A Survey of World Resources}

IN a report on "The Problem of Raw Materials" prepared by Prof. I. Högbom, of Stockholm, and issued by the League of Nations in 1937, there is a striking graph showing the world production of the principal minerals and metals during the period 1860-1937. Sir Harold Hartley uses this graph as the text of an article, published in The Times of November 27, on the need for a survey of world resources. The graph is plotted on a logarithmic scale and demonstrates that production of aluminium, tin, copper, phosphates, petroleum, pig iron, coal and lignite had a steady rate of growth until 1914. Then the general rate decreases sharply, to be followed by violent oscillations during the past twenty-five years. The end of the period of steady increase marked the end of territorial expansion and exploitation, accompanied by failure to realize that world conditions had changed, and that a planned economy was required. Such a plan is implicit in the orderly economic collaboration of the United Nations envisaged in the Atlantic Charter. The goal is "greater stability of world conditions and increased well-being based on the better use of world resources, full employment and the development of backward areas". The foundation of any scheme directed towards this end is a world survey of production and consumption.

Sir Harold points out that the data for the prewar years are mainly available, though they need bringing together, and the Allied Bureau under Sir Frederick Leith-Ross is dealing with the immediate post-war period. The preparation of estimates for a more stable form of society to succeed this period is a more difficult matter, in view of the fluctuations of the past twenty years. Such long-range estimates must be 'moving targets' subject to such factors as population trends, knowledge of basic needs and the development of backward countries. Estimates of consumption must precede estimates of production, to be followed by surveys of distribution. The data for these estimates, some of them already available through the activities of individual countries and industries, or committees set up by the United Nations, are at present unco-ordinated, with unknown gaps, and, in Sir Harold Hartley's opinion, a United Nations Economic Bureau should be appointed to deal with the matter.

\section{Temperature of the Atmosphere}

A FURTher colloquium in the series arranged by the Manchester University Branch of the Association of Scientific Workers was addressed by Dr. T. G. Cowling on December 2, the title being "The Temperature of the Atmosphere". Dr. Cowling began by describing how the temperature of the lower part of the atmosphere is determined by radiation, convection, and advection (horizontal currents of air and water). The distribution of temperature over the earth's surface varies with the season, and in consequence sudden large fluctuations in temperature due to the passage of air masses are in the British Isles more probable during winter than summer. Turning to the variation of temperature with altitude, Dr. Cowling suggested a possible explanation for the fact that the temperature ceases to decrease at a height known as the tropopause. According to this theory, solar energy is absorbed by ozone in the stratosphere, and in the absence of any gas with strong emission bands in the infra-red, the temperature is increased. Water vapour has broad intense bands in the infra-red, and when it is present tends to keep the temperature low. In considering variations of the temperature in the stratosphere with season and latitude, account must be taken of any variations of the concentrations of 
gases such as ozone and water vapour, as well as of the intensities of the radiations coming from the sun and earth. During the discussion which followed, Dr. L. Jánossy pointed out that the tropopause falls rapidly at the same latitude that shows a marked increase in cosmic ray intensity. Cosmic rays might conceivably produce some ozone, and so account for the higher temperatures over the poles.

\section{Recent Earthquakes}

The United States Coast and Geodetic Survey, in co-operation with Science Service and the Jesuit Seismological Association, has determined the epicentres of two recent earthquakes. The first was on September 26, 1942, and took place at approximately 4h. $00 \cdot 3 \mathrm{~m}$. U.T. It had an epicentre near lat. $12 \cdot 8^{\circ} \mathrm{N}$., long. $87.5^{\circ} \mathrm{W}$., which is in the region south of the Golfo de Fonseca in Nicaragua in Central America. The second occurred on October 21, 1942, at about 16h. $22 \mathrm{~m}$. 15s. U.T. and had an epicentre near lat. $33 \cdot 1^{\circ} \mathrm{N}$., long. $116 \cdot 0^{\circ} \mathrm{W}$., which is to the west-northwest of Imperial in Southern California.

That the earth blocks, the movement of which caused the very severe earthquake of December 27, 1939 in Anatolia, have not yet attained their position of equilibrium is shown by the earthquakes and tremors which still occur in the district. The latest strong shock of this series occurred about 10 p.m. local time on December 3. At Ciorum, sixty miles from Ankara, the tremors lasted 25 seconds according to human perception. Four people are reported to have lost their lives and nine were injured in Central Anatolia.

\section{Sir William Power, F.R.S. (1842-1916)}

Sir Wruliam Henry Powkr, an eminent Victorian epidemiologist, was born at Bosworth on December 15, 1842, the son of a medical practitioner. $\mathrm{He}$ was educated at University College, London, and qualified in 1864. After serving as resident medical officer at the Victoria Hospital for Diseases of the Chest, where he gained much valuable information in connexion with tuberculosis, he was appointed in 1871 temporary medical inspector in the Local Government Board, where he made a special study of the small-pox epidemics in London of 1871-72 and 1881 and upheld the theory of the aerial convection of disease, particularly in relation to the Western Hospital, then known as the Fulham Small-Pox Hospital. The publication of his "Statistics of Small-pox Incidence in the Registration Districts of London relating to the Operation of Small-pox Hospitals in the Metropolis" led to the permanent removal of all small-pox cases occurring in London to extra-metropolitan hospitals, a practice which still holds good. His other publications included reports on epidemics of diphtheria in Warwickshire and Essex, an outbreak of scarlet fever in certain districts of London believed to be due to milk, and lead poisoning by public water supplies. In 1871 he was appointed assistant medical officer in the Local Government Board, and in 1889 succeeded Sir Richard Thorne Thorne as senior medical officer, when he did valuable work in connexion with the Food and Drugs Aets and the Royal Commission on Tuberculosis. In 1895 he was elected a fellow of the Royal Society. He was also awarded the Jenner Medal of the Epidemiological Society of London, the Bissett-Hawkins Medal of the Royal College of Physicians and the Stewart Prize of the British Medieal Association. He died on July 28, 1916.

\section{Marius Sophia Lie (1842-1899)}

ON December 17 occurs the centenary of the birth of the distinguished Norwegian mathematician Marius Sophia Lie, who was born at Nordfjordeif, near Bergen. Educated at the University of Christiania (Oslo), he took his doctonate in 1868 and, after gaining a travelling scholarship, visited France and Germany, making the acquaintance of Klein, Darboux and Jordan. In 1872 a special chair of mathematics was created for him at Christiania, but fourteen years later he returned to Germany to succeed Klein at Leipzig. He returned to the Norwegian capital in 1898 , and died there on February 18, 1899. Lie was recognized as one of the most original and independent workers in pure mathematics; he was elected a foreign member of the Royal Society, and the Cambridge Philosophical Society and the London Mathematical Society added his name to their lists of honorary members. Referring to his death, Larmor said, at the meeting of the British Association in 1900, "We have lost one of the greatest constructive mathematicians of this century, who has in various directions fundamentally expanded the methods and conceptions of analysis by reverting to the fountain of direct geometrical intuition".

\section{Admiralty Appointments}

THE appointment is announced of Commander C. F. Goodeve, F.R.S., R.N.V.R., reader in physical chemistry at University College, University of London, to the post of assistant controller (research and development) in the Admiralty. Commander Goodeve will be responsible for the co-ordination of research and development in the departments of the Controller of the Navy, and for ensuring that scientific opinion is adequately represented in those Departments and that due weight is given to it.

Sir Stanley V. Goodall, director of naval construction, has been given the additional appointment of assistant controller for warship production. $\mathrm{He}$ will remain the principal technical adviser to the Board of Admiralty on the design of warships and other vessels for the Royal Navy. In his capacity as assistant controller for warship production he will be responsible under the Controller of the Navy for the produc. tion of warships and their completion with all appropriate supplies, and for the necessary co-ordination to achieve the fastest possible results with the greatest economy of effort.

\section{Announcements}

Sir John Russell retires on September 30, 1943, under the age limit, from the directorship of the Rothamsted Experimental Station. Sir John Russell succeeded Sir Daniel Hall in 1912 and during his thirty-one years as director the Station, the oldest agricultural institute in the world, has shown a remarkable expansion of its research activities and of its authority in agriculture.

Mr. Harry R. Ricardo, who is well known for his outstanding work in connexion with internal combustion engines, has been elected an honorary member of the American Society of Mechanical Engineers, New York.

IN recognition of his distinguished services as rector of the Imperial College of Science and Technology during 1929-42, Sir Henry Tizard, president of Magdalen College, Oxford, has been elected a fellow of the Imperial College. 